\title{
Multimode optoelectrochemical detection of cysteine based on an electrochromic Prussian blue electrode ${ }^{\text {is }}$
}

\author{
Lin-Chi Chen ${ }^{\mathrm{a}}$, Kuo-Chuan Ho ${ }^{\mathrm{b}, \mathrm{c}, *}$ \\ ${ }^{a}$ Department of Bio-Industrial Mechatronics Engineering, National Taiwan University, Taipei 10617, Taiwan \\ ${ }^{\mathrm{b}}$ Department of Chemical Engineering, National Taiwan University, Taipei 10617, Taiwan \\ ${ }^{\mathrm{c}}$ Institute of Polymer Science and Engineering, National Taiwan University, Taipei, 10617, Taiwan
}

Available online 16 September 2007

\begin{abstract}
In the present work, multiple detection modes of an electrochromic (EC) sensor were studied and compared. We utilized a Prussian blue (PB) thin film modified F-doped tin oxide (FTO) electrode to detect L-cysteine (Cys), a naturally occurring amino acid bearing a thiol group. The sensing was triggered by a cyclic voltammetric (CV) scan and functioned upon the catalytic oxidation of Cys at the surface of a PB/FTO electrode that had been oxidized to the Berlin green (BG) state. With the EC property of PB and the use of transparent FTO electrode, the Cys concentration, denoted as [Cys], could be detected both electrochemically and optically. As a result, the following four types of calibration curves were obtained simultaneously from the same in situ optoelectrochemical measurement: amperometry (current versus [Cys]), coulometry (charge versus [Cys]), potentiometry (potential versus [Cys]), and absorptometry (optical density change versus [Cys]). This proof-of-concept study suggests that the EC detection can provide more informative results than pure electrochemical or optical sensing approach does.
\end{abstract}

(C) 2007 Elsevier B.V. All rights reserved.

Keywords: Biosensor; Cysteine (Cys); Electrochromic (EC); Prussian blue (PB); Thiol

\section{Introduction}

Cysteine $\left(\mathrm{C}_{3} \mathrm{H}_{7} \mathrm{NO}_{2} \mathrm{~S}\right)$ is a naturally occurring, sulfurcontaining amino acid that plays many important roles in biological systems, such as detoxification, metabolism, a critical substrate for protein synthesis and folding (formation of disulfide bonds), a precursor for antioxidant glutathione synthesis, and a key extracellular reducing agent [1]. For food industry, cysteine has been used as the raw materials for the production of various flavors [2] and has been served as a processing aid for baking [3]. In clinics, it was reported that altered levels of the plasma Cys could link in many pathological conditions, including Alzheimer's and Parkinson's diseases [4]. For pharmaceutical application, the well-known $N$-acetyl cysteine (NAC), a Cys derivative, is often used as a cough medicine and has been investigated for other new treatments recently [5]. In

\footnotetext{
Manuscript No. TO3.1.5\#355 presented at the 11th International Meeting on Chemical Sensors (IMCS11), 16-19 July 2006, Brescia, Italy.

* Corresponding author at: Department of Chemical Engineering, National Taiwan University, Taipei 10617, Taiwan. Tel.: +8862 23660739 ; fax: +88622362 3040

E-mail address: kcho@ntu.edu.tw (K.-C. Ho).
}

some biotechnology research, cysteine contains a highly nucleophilic thiol group (-SH, also called sulfhydryl group) and is thus a very popular target for site-directed labeling bioassays [6] that investigate biomolecular structure and dynamics. As a consequence, cysteine detection is of great importance for industrial, health care, and fundamental research applications. To date, many analytical approaches have been developed for Cys detection, and they can be categorized into the following two types, electrical detection and optical detection. Electrical Cys detection can be carried out with amperometry [7], potentiometry [8], cyclic voltammetry (CV) [9], and differential pulse voltammetry (DPV) [9]. Optical Cys detection can be done with spectrofluorimetry [10] and colorimetry [11]. Both electrical and optical detection schemes are well-suited for flow injection analysis (FIA) [12] or high-performance liquid chromatography (HPLC) $[13,14]$ that helps in the precise determination of Cys level in body fluids and other biological samples. In order to develop a Cys sensor that generates both electrical and optical signals simultaneously for more informative detection, an electrochromic Prussian blue (PB) thin film electrode was used as the transducer for Cys sensing in this work.

An electrochromic (EC) material changes color when its redox state is altered electrochemically. Based on this property, 
a variety of EC thin films have been synthesized and deposited onto optically transparent electrodes (OTEs), such as F-doped tin oxide (FTO) and indium tin oxide (ITO) glasses, for assembling into a unique class of electro-optical devices, namely electrochromic devices (ECDs) [15]. For instance, Prussian blue (PB, $\left.\mathrm{KFe}^{\mathrm{III}}\left[\mathrm{Fe}^{\mathrm{II}}(\mathrm{CN})_{6}\right]\right)$, a classical dark blue pigment, is one of the frequently used EC materials [16]. When deposited on an OTE, Prussian blue is able to exhibit a reversible transparent-blue-green multiple color change corresponding to the following redox states: Prussian white $\left(\mathrm{PW}, \mathrm{K}_{2} \mathrm{Fe}^{\mathrm{II}}\left[\mathrm{Fe}^{\mathrm{II}}(\mathrm{CN})_{6}\right]\right), \mathrm{PB}$, and Berlin green (BG, $\left.\left\{\mathrm{KFe}^{\mathrm{III}}\left[\mathrm{Fe}^{\mathrm{II}}(\mathrm{CN})_{6}\right]\right\}_{1 / 3}\left\{\mathrm{Fe}^{\mathrm{III}}\left[\mathrm{Fe}^{\mathrm{III}}(\mathrm{CN})_{6}\right]\right\}_{2 / 3}\right)$. Hence, Prussian blue-based ECDs have been investigated for the applications in commercial displays, smart daylighting-control windows, anti-glare rearview mirrors, and sunglasses [17]. Here we demonstrate another promising application of EC thin films - a novel biosensing approach with real-time multiple detection modes - by the PB-modified FTO electrode (denoted as PB/FTO).

In fact, most of the EC materials also can serve as solidstate redox mediators or recognition elements for their superior electrocatalytic activity to certain biomolecules and high ion selectivity. Hence, a variety of electrode materials, such as glassy carbon [18], graphite [19], carbon paste [20], Pt [21], gold [22], ITO [23], and FTO [24], have been modified with PB thin films for electrochemical sensor research and development. Some of the PB electrochemical sensors are based on the function of high selectivity of counter ions [25,26]. Other systems employ direct electrocatalysis strategy, such as detection of hydrogen peroxide [18,21,24], cysteine [13], morphine [23], and so on. The others take effect via coupling with redox enzymes [19,20] like glucose oxidase [27,28], alcohol oxidase [28], and cholesterol oxidase [29], just to name a few. The comprehensive discussions over PB-based biosensors can be found in the recent review articles [30,31]. In addition to electrochemical detection, many efforts had been made to develop optical sensors based on the photosynthesized PB/polymer composite film [32-36] or PB-immobilized beads [37]. In general, such a PB-based optical biosensor worked through the absorptometric detection of analyte-induced PB/PW interchange. For example, the PB film chemically deposited on a non-conductive, transparent substrate could be reduced by a reductant like ascorbic acid [32-34,37] and thus exhibited a blue-to-colorless optical change; on the other hand, the colorless PW film could be oxidized to PB (blue state) by an oxidant like hydrogen peroxide $[33,34]$. This approach could be used to fabricate an optical glucose [35] and urea [36] biosensor for flow injection analysis, when enzymes were entrapped into the PB films. But, different from a typical amperometric sensor, the optical sensors utilized chemical method to regenerate the PB mediator in stead of applying a dc bias and might therefore elongate the recovery time before the next sensing experiment. In contrast, what we developed in this work is a new biosensing approach, featuring both electrochemical and optical detections by taking advantages of the EC property of PB thin film. To validate the EC sensing method, cysteine (Cys) was chosen as a model analyte.
In the following sections, we will report an in situ optoelectrochemical Cys measurement at a PB/FTO electrode that electrocatalyzes Cys in a buffered solution by a voltammetric scan. Through simultaneous analysis of voltammetric and voltabsorptometric responses [38], our new detection scheme is able to generate amperometric, coulometric, potentiometric, and absorptometric data in a single sensing experiment. It will be shown that EC sensing can provide more informative data than pure amperometric or optical detection does. In addition, the mechanism of EC sensing will be discussed.

\section{Experimental}

\subsection{Materials and instrumentation}

The main chemicals used in this work were $\mathrm{FeCl}_{3}$, $\mathrm{K}_{3} \mathrm{Fe}(\mathrm{CN})_{6}, \mathrm{KCl}, \mathrm{HCl}, \mathrm{H}_{3} \mathrm{PO}_{4}, \mathrm{KH}_{2} \mathrm{PO}_{4}$, and L-cysteine. All of them were ACS reagent grade and not further purified. Deionized water (DIW) was used throughout. F-doped $\mathrm{SnO}_{2}$ (FTO)-coated glass substrates $\left(R_{\mathrm{Sh}}=20 \Omega / \square\right.$ and $2 \mathrm{~mm}$ in thickness) were obtained from a local supplier (Sinonar Corporation, Hsinchu, Taiwan). Before using, FTO glass substrates were washed ultrasonically with $0.1 \mathrm{~N} \mathrm{HCl}$ for $5 \mathrm{~min}$ and with DIW for another $5 \mathrm{~min}$. After an extra DIW rinse, the substrates were dried in air. When preparing a FTO electrode, a piece of cooper tape (3 M Company), serving as the bus bar, was applied to the top edge of the FTO-coated surface, and then an insulating tape was applied to the same surface of glass substrate to define an active electrode area of $3.0 \mathrm{~cm} \times 1.5 \mathrm{~cm}$.

All of the electrochemical experiments were performed in a static, three-electrode fashion. A homemade $\mathrm{Ag} / \mathrm{AgCl} / \mathrm{sat}$ 'd $\mathrm{KCl}$ reference electrode $(-94.7 \mathrm{mV}$ versus commercial $\mathrm{SCE})$ and a Pt coil counter electrode were used. All electrochemical experiments were controlled and monitored using a potentiostat/galvanostat (Autolab, model PGSTAT30), including electrodeposition of PB thin films and in situ optoelectrochemical detection of Cys. A UV-vis spectrophotometer (Shimadzu, model UV-1601PC) was used to collect absorptometric data. All of the experiments were done at room temperature.

\subsection{Electrodeposition of PB thin films on FTO glass substrates}

Electrodeposition of PB thin films on FTO glass substrates (active area $=3.0 \mathrm{~cm} \times 1.5 \mathrm{~cm}$ ) was done by applying a cathodic current density of $20 \mathrm{uA} / \mathrm{cm}^{2}$ for $900 \mathrm{~s}$, i.e., total charge capacity input for the deposition was equal to $18.0 \mathrm{mC} / \mathrm{cm}^{2}$. The deposition bath was composed of $10 \mathrm{mM} \mathrm{K}_{3} \mathrm{Fe}(\mathrm{CN})_{6}, 10 \mathrm{mM}$ $\mathrm{FeCl}_{3}, 0.1 \mathrm{M} \mathrm{KCl}$, and 1.0 M HCl. Presumably, the PB thin film deposited in a $\mathrm{KCl}$-containing solution was the soluble form $\left(\mathrm{KFe}^{\mathrm{III}}\left[\mathrm{Fe}^{\mathrm{II}}(\mathrm{CN})_{6}\right]\right)[16,30,31]$. The as-prepared PB modified FTO electrodes (PB/FTO) were washed with DIW and were then dried in air for at least $24 \mathrm{~h}$ prior to use. A typical charge capacity of the PB thin film was $c a .14 .0 \mathrm{mC} / \mathrm{cm}^{2}$ that was estimated from the voltammogram of $\mathrm{PB} / \mathrm{PW}$ redox reaction in a $0.1 \mathrm{M}$ potassium phosphate buffer, $\mathrm{pH} 2.5$ (scan range $=0.6$ to $-0.2 \mathrm{~V}$ versus $\mathrm{Ag} / \mathrm{AgCl} / \mathrm{sat}^{\prime} \mathrm{KCl}$; scan rate, $v=5 \mathrm{mV} / \mathrm{s}$ ). This sug- 


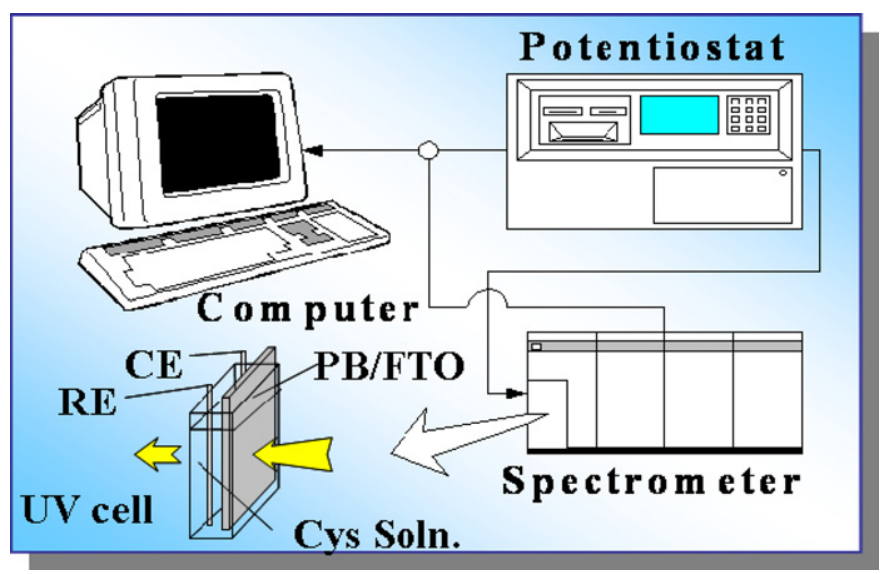

Fig. 1. Schematic apparatus for the in situ spectroelectrochemical Cys detection with a PB/FTO working electrode (RE \& CE: reference \& counter electrodes).

gests a deposition efficiency of $77.8 \%$ (= redox capacity/current density input while deposition $=14.0 / 18.0)$.

\subsection{In situ optoelectrochemical cysteine detection at a PB/FTO electrode}

The schematic apparatus for the in situ optoelectrochemical Cys detection is drawn in Fig. 1, which is very similar to that of our previous work [38]. The EC sensing took place in a UV cell $(4 \mathrm{~cm} \times 4 \mathrm{~cm} \times 1 \mathrm{~cm})$ positioned in the UV-vis spectrometer. The UV cell not only filled with an analyte solution but also equipped with a wired PB/FTO working electrode, a homemade reference electrode $(\mathrm{Ag} / \mathrm{AgCl} / \mathrm{sat}$ 'd $\mathrm{KCl})$, and a $\mathrm{Pt}$ coil counter electrode. The analyte solution was buffered with $0.1 \mathrm{M} \mathrm{H}_{3} \mathrm{PO}_{4}$ and $0.1 \mathrm{M} \mathrm{KH}_{2} \mathrm{PO}_{4}(\mathrm{pH} 2.5)$ and contained 0 , $0.08,0.04,0.2,1,5$, or $25 \mathrm{mM}$ cysteine. The acidity ( $\mathrm{pH} 2.5$ ) was required for stabilizing the deposited $\mathrm{PB}$ thin film without the aid of a polymer matrix, carbon paste, or other binder material $[16,30,31]$, as such an additive might interfere with the proofof-concept EC sensing. Then the EC detection was triggered by cyclic voltammetry $(\mathrm{CV})$ with the potentiostat, scanning back and forth between $0.6 \mathrm{~V}(\mathrm{~PB})$ and $-0.2 \mathrm{~V}(\mathrm{PW})$ and/or $+0.6 \mathrm{~V}$ $(\mathrm{PB})$ and $+1.2 \mathrm{~V}(\mathrm{BG})$ (versus $\mathrm{Ag} / \mathrm{AgCl} / \mathrm{sat}$ 'd $\mathrm{KCl}$ ) at a scan rate of $5 \mathrm{mV} / \mathrm{s}$. Finally, voltammograms and voltabsorptometric responses at $690 \mathrm{~nm}$ [38] obtained at different Cys concentrations were collected simultaneously and analyzed.

\section{Results and discussions}

\subsection{Detection of cysteine at an electrochromic PB/FTO electrode}

The oxidized state of PB thin film, Berlin green (BG), can be viewed as an artificial oxidase for some reductant-like biomolecules such as morphine [23] and cysteine [13]. Especially, it was reported that Cys (denoted as RSH) could be oxidized to disulfide cystine (denoted as RSSR) by BG that was then reduced to $\mathrm{PB}$ via acquiring both electrons and potassium ions (counter ions), and BG was regenerated under a positive bias, sufficiently larger than the standard potential of the

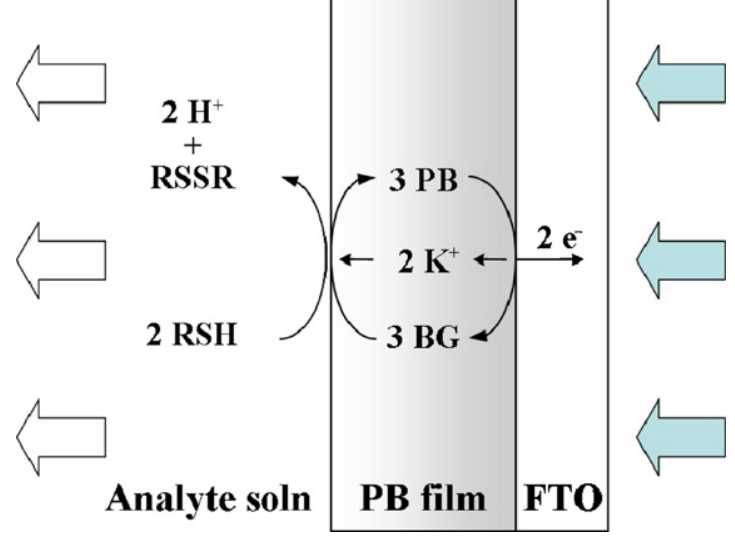

Fig. 2. Schematic illustration for the mechanism of electrochromic sensing of Cys at a PB/FTO electrode (RSH: cysteine; RSSR: cystine).

BG/PB redox system (ca. $0.9 \mathrm{~V}$ versus $\mathrm{Ag} / \mathrm{AgCl}$ ), for continuous interrogation of Cys [13]. According to the above fact and the electrochemistry of "soluble-form" PB [16,30,31], we propose a working principle for the EC detection of Cys at a $\mathrm{PB} / \mathrm{FTO}$ electrode, as shown in Fig. 2. The mechanism also can be illustrated by the following equations:

$$
3 \mathrm{~PB} \leftrightarrow 3 \mathrm{BG}+2 \mathrm{~K}^{+}+2 \mathrm{e}^{-}
$$

(electro-oxidation of $\mathrm{PB}$ to $\mathrm{BG}$ )

$$
\begin{aligned}
3 \mathrm{BG}+2 \mathrm{RSH}+2 \mathrm{~K}^{+} \rightarrow & 3 \mathrm{~PB}+\mathrm{RSSR}+2 \mathrm{H}^{+} \\
& \text {(chemical oxidation of Cys) }
\end{aligned}
$$

The mechanism is a reversible electrochemical as well as EC reaction followed by an irreversible chemical oxidation. Therefore, we considered that not only electrochemistry but also spectroscopic behavior of PB would be affected by the BG-induced Cys oxidation and thus influenced by the Cys concentration (denoted as [Cys]).

In this study, we triggered the EC detection by a cyclic voltammetric scan $(v=5 \mathrm{mV} / \mathrm{s})$, and we followed Fig. 2 to simultaneously monitor voltammograms and voltabsorptometric responses at $690 \mathrm{~nm}$, a characteristic wavelength of $\mathrm{PB}$ thin film [38], of PB/FTO in buffered Cys solutions. Before that, we had assured cycling stability of $\mathrm{PB} / \mathrm{FTO}$ in $0.1 \mathrm{M}$ $\mathrm{H}_{3} \mathrm{PO}_{4} / \mathrm{KH}_{2} \mathrm{PO}_{4}$ (pH 2.5) (both $\mathrm{PB} / \mathrm{PW}$ and $\mathrm{BG} / \mathrm{PB}$ redox systems) and observed a decrease in optical density (OD) at $690 \mathrm{~nm}$ for both PB-to-PW $(0.6 \mathrm{~V} \rightarrow-0.2 \mathrm{~V})$ and PB-to-BG $(0.6 \mathrm{~V} \rightarrow 1.2 \mathrm{~V})$ electrochromism. The data are shown in Fig. 3 . The results of different Cys detection methods (voltammetry, voltabsorptometry, and differential voltabsorptometry) degenerated from the same in situ optoelectrochemical experiment are presented and discussed as follows.

\subsection{Voltammetric detection of cysteine at PB/FTO}

Basically, the cyclic voltammograms (CVs) responded to the entire process of electrocatalytic Cys oxidation at a PB/FTO electrode, i.e., both Eqs. (1) and (2). But, we found that the 


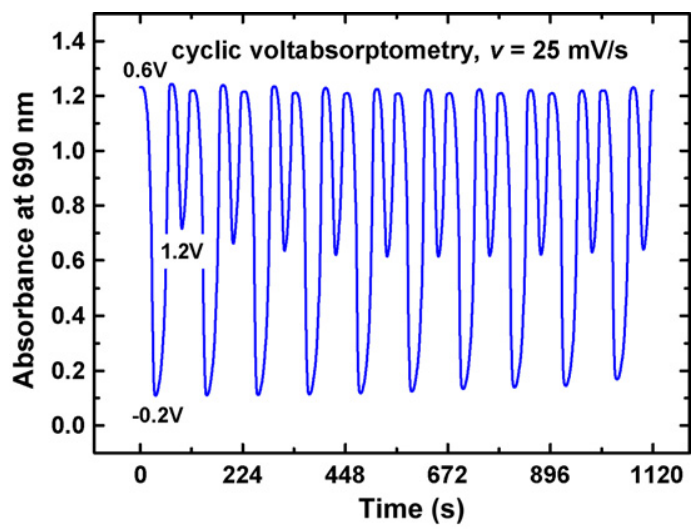

Fig. 3. Cyclic voltabsorptometric (CVA) response of a $\mathrm{PB} / \mathrm{FTO}$ electrode in $0.1 \mathrm{M} \mathrm{H}_{3} \mathrm{PO}_{4}$ and $\mathrm{KH}_{2} \mathrm{PO}_{4}, \mathrm{pH} 2.5$ at a scan rate $(v)$ of $25 \mathrm{mV} / \mathrm{s}$.

$\mathrm{CV}$ behavior of PB/FTO was not altered significantly when [Cys] was lower than $40 \mu \mathrm{M}$ (data not shown). Fig. 4 shows the CVs of PB/FTO measured in the phosphate-buffered solutions containing $0.2,1,5$, and $25 \mathrm{mM}$ Cys. It can be seen that the $\mathrm{PB} / \mathrm{PW}$ redox wave (ranged between -0.2 and $0.6 \mathrm{~V}$ ) is not changed with [Cys], except for the case of [Cys] $=25 \mathrm{mM}$. Presumably, cysteine ( $\mathrm{p} I=5.0$ [1]) must be positively charged at $\mathrm{pH} 2.5$ and might then compete with reversible, potassium counter ions $[25,26]$ (from $0.1 \mathrm{M} \mathrm{KH}_{2} \mathrm{PO}_{4}$ ) for the PB-to-PW redox reaction at such a concentration level $([\mathrm{Cys}]=25 \mathrm{mM})$. By contrast, the BG/PB redox wave (ranged between 0.6 and $1.2 \mathrm{~V}$ ) becomes more and more asymmetric and distorted to the anodic side when [Cys] increases. This corresponds to the mechanism mentioned in Section 3.1.

Since Fig. 4 is a typical electrocatalytic data, both amperometric and coulometric detections of Cys can be achieved by plotting calibration curves from the $\mathrm{CV}$ responses. Fig. 5 compares two amperometric calibration curves obtained from anodic peak current density and sampling current density at $1.2 \mathrm{~V}$ (versus $\mathrm{Ag} / \mathrm{AgCl} / \mathrm{sat}$ 'd $\mathrm{KCl})$. It can be found that the sampling current method provides both larger dynamic range and sensitivity than the peak current picking does. This is because more $\mathrm{BG}$ forms at $1.2 \mathrm{~V}$ than at the peak potential of $\mathrm{BG} / \mathrm{PB}$ redox wave, although Cys addition tends to shift the peak potential

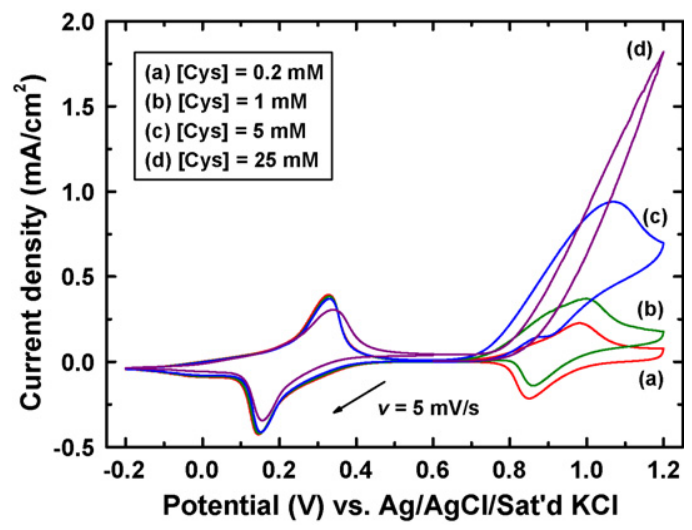

Fig. 4. Cyclic voltammograms (CVs) of a PB/FTO electrode in phosphatebuffered cysteine solutions $(\mathrm{pH} 2.5)$ at a scan rate $(v)$ of $5 \mathrm{mV} / \mathrm{s}$.

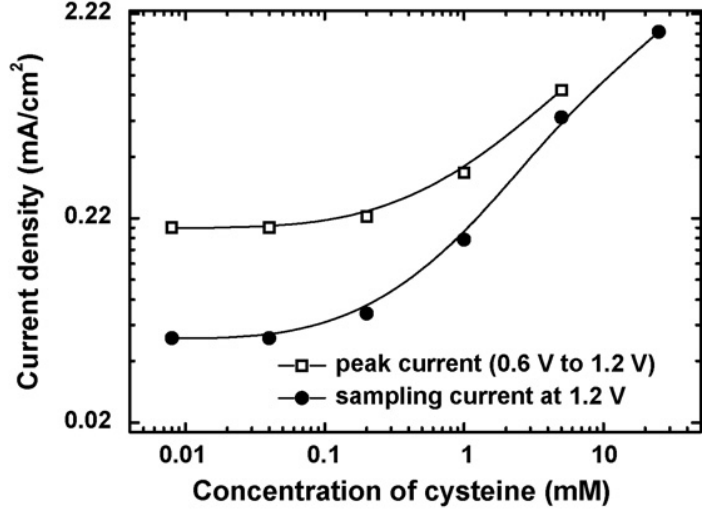

Fig. 5. Plots of voltammetric peak current density (of the anodic wave) and sampling current density (at $1.2 \mathrm{~V}$ vs. $\mathrm{Ag} / \mathrm{AgCl} / \mathrm{sat}$ 'd $\mathrm{KCl}$ ) against cysteine concentration. The data were obtained from the CVs like those shown in Fig. 4.

anodically. A more reliable electrochemical calibration curve is to plot the total reacted charge against analyte concentration, as shown in Fig. 6. The coulometric detection is done by mathematical integration of anodic current density ranged between 0.6 to $1.2 \mathrm{~V}$ for each $\mathrm{CV}$ data obtained at different Cys concentrations. The method can provide accurate concentration calibration as every electron involved in the electrocatalytic process has been counted. The limit of detection (LOD) for both electrochemical methods is $c a .40 \mu \mathrm{M}$ and corresponds to the value reported in literature [13].

\subsection{Voltabsorptometric detection of cysteine at PB/FTO}

Since both Cys (RSH) and disulfide cystine (RSSR) are colorless within the visible spectrum, the optical density (OD) change at $690 \mathrm{~nm}$ responds to the $\mathrm{EC}$ reaction at the $\mathrm{PB} / \mathrm{FTO}$ electrode. It has been shown in Fig. 3 that the conversion of BG from $\mathrm{PB}$ causes OD attenuation at $690 \mathrm{~nm}$. By real-time absorbance measurement during the $\mathrm{CV}$ scan, we observed that increasing Cys in the analyte solution would reduce and finally eliminate the OD attenuation. The cyclic voltabsorptometric (CVA, absorbance versus time) data are given in Fig. 7. (Note: The data for $\mathrm{PB} / \mathrm{PW}$ interchange and for $[\mathrm{Cys}]<0.2 \mathrm{mM}$ are not shown.)

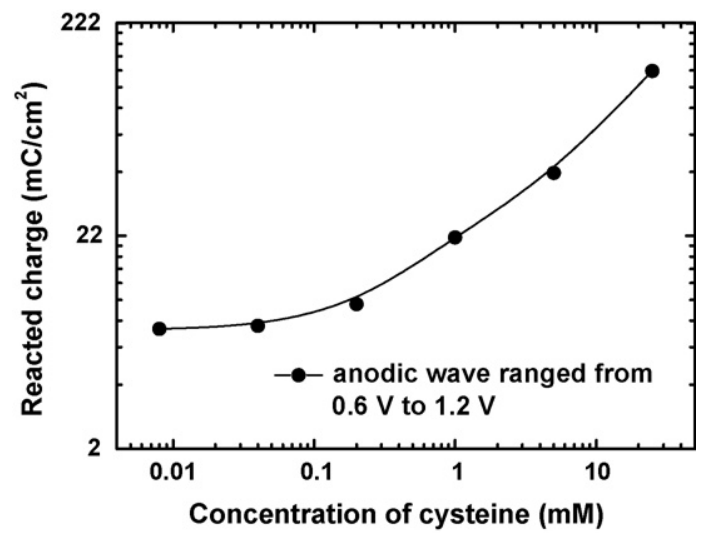

Fig. 6. Plot of reacted charge density against cysteine concentration. The data were obtained by integration of anodic current density ranged from 0.6 to $1.2 \mathrm{~V}$ in the CVs like those shown in Fig. 4. 


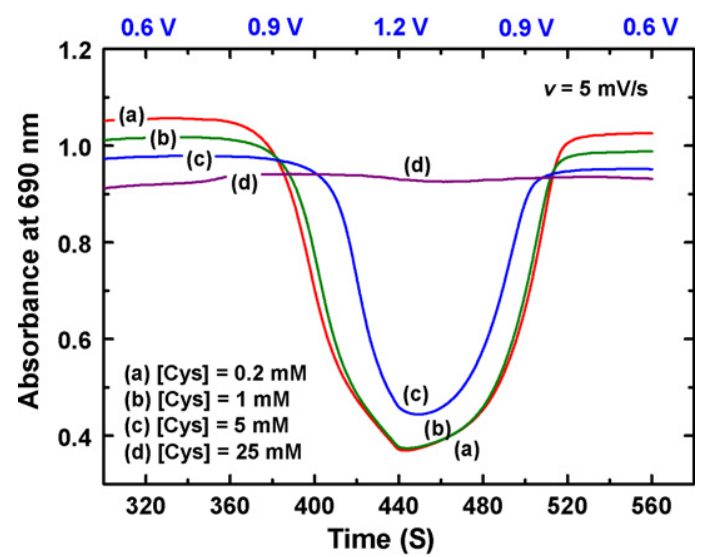

Fig. 7. Curves of cyclic voltabsorptometry (CVA) of a PB/FTO electrode in phosphate-buffered cysteine solutions $(\mathrm{pH} 2.5)$ at a scan rate $(v)$ of $5 \mathrm{mV} / \mathrm{s}$. The data were obtained along with CVs in Fig. 4, and only the PB/BG electrochromic behaviors are shown here.

Although the initial absorbance shifts at $0.6 \mathrm{~V}$ (the PB state) might be due to operating factors like changing analyte solutions, a conclusive finding in Fig. 7 revealed that high [Cys] $(>1 \mathrm{mM})$ interferes the formation of BG from PB. Especially for the case of $[\mathrm{Cys}]=25 \mathrm{mM}$, Berlin green seems never being formed or not detectable throughout the potential-scanning range (0.6-1.2 V). Such a phenomenon would not be discovered using an ordinary amperometric or voltammetric detection and under a facile redox mediator assumption. However, Fig. 7 serves as an evidence to our proposed model in Fig. 2 that the BG/PB EC reaction, Eq. (1), would be affected by the BG-induced Cys oxidation, as seen in Eq. (2).

Therefore, when the rate of Cys-induced BG reduction (an alternative explanation of Eq. (2)) is faster than the electrochemical oxidation of $\mathrm{PB}$, the OD change $(\triangle \mathrm{OD})$ at $690 \mathrm{~nm}$ can become a measure of [Cys], similar to those reported in PB-based optical sensors [32-37]. Fig. 8 plots $\triangle O D$ at $690 \mathrm{~nm}$ against [Cys] and can thus play the role of a calibration curve for the optical or absorptometric detection. Different from Figs. 5 and 6, the optical calibration is rather non-linear, and the sensitivity is significantly enlarged when $[\mathrm{Cys}]>1 \mathrm{mM}$.

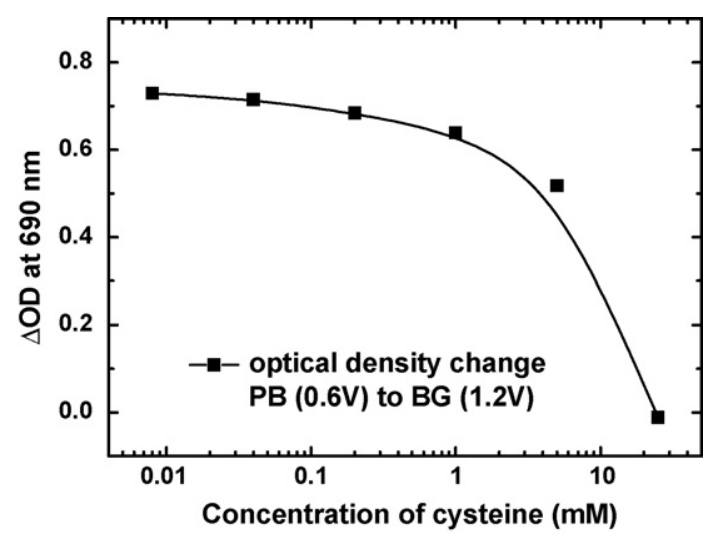

Fig. 8. Plot of optical density change $(\triangle \mathrm{OD})$ at $690 \mathrm{~nm}$ against cysteine concentration. $\triangle \mathrm{OD}=\mathrm{OD}(0.6 \mathrm{~V})-\mathrm{OD}(1.2 \mathrm{~V})$. The data were obtained from the CVA curves like those shown in Fig. 7.
Besides, it contains both upper and lower detection limits. As the lower limit is $c a .40 \mu \mathrm{M}$, the upper limit is $25 \mathrm{mM}$ in the present case attributed to total elimination of BG formation. We believe that the thickness as well as the charge capacity of PB thin film may be another key factor for the dynamic range of the absorptometric detection.

\subsection{Differential voltabsorptometric detection of cysteine at PB/FTO}

To further investigate how the Cys-induced BG reduction affects the PB-to-BG electrochromism, we differentiate cyclic voltabsorptometric (CVA) responses shown in Fig. 7. Fig. 9 presents the differential cyclic voltabsorptometric (DCVA, $\mathrm{d} A / \mathrm{d} t$ versus time) data obtained in $0.2,1,5$, and $25 \mathrm{mM}$ Cys solutions. (Note: no significant difference between DCVA responses for Cys concentration $<0.2 \mathrm{mM}$ is found.) Since the DCVA data can be regarded as optical CV curves [38] and do not respond to thiols, the BG/PB redox mechanism in the presence of Cys can be determined more precisely than that of real, electrochemical CV curves. From Fig. 9, it can be inferred that the PB-to-BG conversion is retarded by the Cys-induced BG reduction, and thus more positive potential is required to regenerate an observable amount of BG. Because of the retardation, the extension of PBto-BG EC reaction is reduced. For the case of $25 \mathrm{mM}$ Cys, the DCVA response is not observable. And this implies that the seriously distorted anodic wave $(0.6 \mathrm{~V} \rightarrow 1.2 \mathrm{~V})$ for $[\mathrm{Cys}]=25 \mathrm{mM}$ in Fig. 4 responds to Cys oxidation only.

On the basis of the peak shift in the BG/PB redox wave, the potentiometric detection of Cys from the same in situ optoelectrochemical measurement is possible. Fig. 10 presents the relationship between both anodic peak potential values obtained from CV and DCVA data and [Cys]. The trends for both peak potentials are similar, and the values determined from DCVA curves (Fig. 9) are slightly higher than those from CV data (Fig. 4). However, the dynamic range and limit of detection ( $c a$. $200 \mu \mathrm{M}$ ) of the potentiometric calibration curve are obviously worse than those of amperometric, coulometric, and absorptometric detection modes.

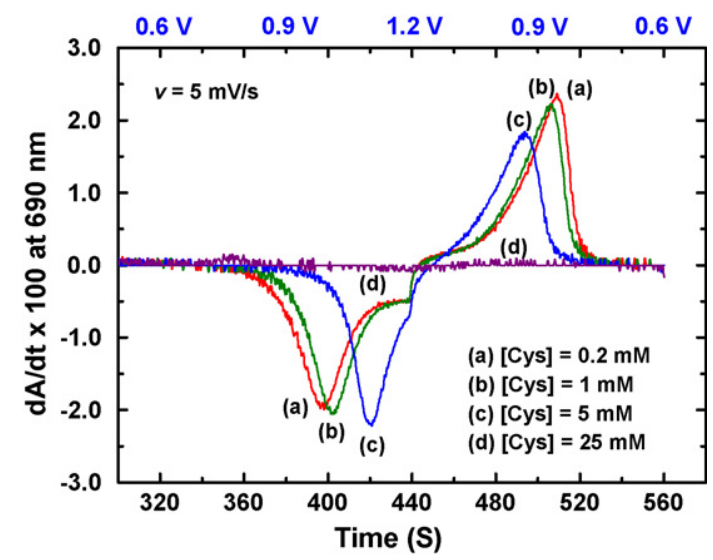

Fig. 9. Curves of differential cyclic voltabsorptometry (DCVA) of a PB/FTO electrode in phosphate-buffered cysteine solutions $(\mathrm{pH} 2.5)$ at a scan rate $(v)$ of $5 \mathrm{mV} / \mathrm{s}$. The data were obtained by differentiation of the CVA curves in Fig. 7 against time. 


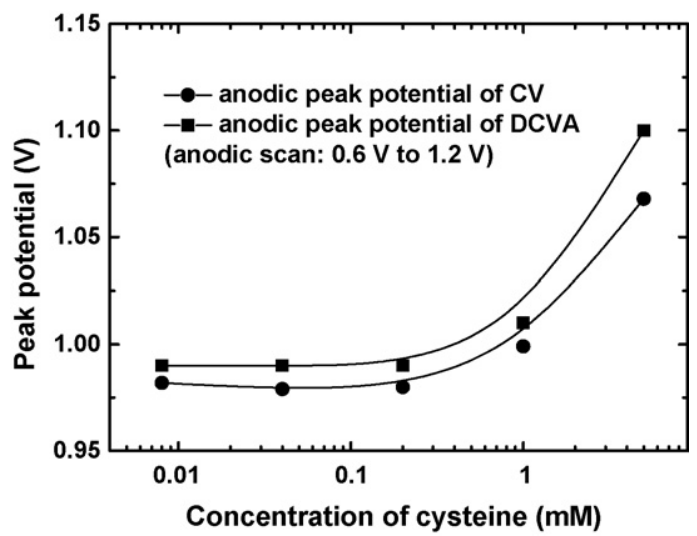

Fig. 10. Plots of voltammetric peak potentials (from both CV and DCVA measurements) against cysteine concentration. The data were obtained from those like Figs. 4 and 9.

Table 1

Detection limits estimated for each sensing scheme in this work

\begin{tabular}{lcl}
\hline Method & $\begin{array}{l}\text { Lower detection limit } \\
(\mu \mathrm{M})\end{array}$ & Upper detection limit \\
\hline Amperometric detection & 40 & Not observed \\
Coulometric detection & 40 & Not observed \\
Potentiometric detection & 200 & within 5-25 mM \\
Absorptometric detection & 40 & $25 \mathrm{mM}$ \\
\hline
\end{tabular}

\section{Conclusions}

We have demonstrated the new application of EC thin film for biosensors through the in situ optoelectrochemical Cys detection at a PB/FTO electrode. It has been shown that at least four types of calibration curves can be obtained simultaneously from the EC detection triggered by a single CV scan: they are amperometry (current versus [Cys]), coulometry (charge versus $[\mathrm{Cys}]$ ), potentiometry (potential versus [Cys]), and absorptometry (absorbance versus [Cys]). This suggests that the EC detection can provide more informative results than sole electrochemical or optical sensing approach does. Table 1 summarizes the estimated limits of detection for each sensing scheme in the present work. Since the normal concentration of plasma Cys in a healthy person is in the range between 152.8 and $378.0 \mu \mathrm{M}$, our EC detection is applicable for clinical purposes. Moreover, such a sensing method can be coupled with liquid chromatography $[13,14,39]$ or other separation techniques to detect other organic thiols, Cys-rich proteins, or thiol-labeled biomolecules for many purposes. Besides, there exist many other EC thin film materials, like transition metal oxides and conducting polymers $[15,17]$, to provide a variety of choices of scanning potential range and characteristic wavelength for different EC biosensing applications against different biomolecular targets.

\section{Acknowledgements}

This work was sponsored by the National Research Council of the Republic of China (Taiwan) under grant numbers NSC 94-2214-E-002-021 and NSC 96-2221-E-002-170.

\section{References}

[1] J.M. Berg, J.L. Tymoczko, L. Stryer, Biochemistry, 5th ed., W.H. Freeman and Co., NY, USA, 2002.

[2] A. Yaghmur, A. Aserin, N. Garti, Eurfural-cysteine model reaction in food grade noionic oil/water microemulsions for selective flavor formation, J. Agric. Food Chem. 50 (2002) 2878-2883.

[3] D.L. Frape, J. Wilkinson, L.G. Chubba, A.M. Buchanan, J.B. Coppock, Use of L-cysteine in bread baking-results of a multi-generation feeding experiment with breeding rats, J. Sci. Food Agric. 22 (1971) 65-68.

[4] M.T. Heafield, S. Fearn, G.B. Sterevton, R.H. Waring, A.C. Willams, S.G. Sturman, Plasma cysteine and sulphate levels in patients with motor neurone, Parkinson's and Alzheimer's disease, Neurosci. Lett. 110 (1990) 216-220.

[5] M.L. Aitio, $N$-acetylcysteine - passé-partout or much ado about nothing? Br. J. Clin. Pharmacol. 61 (2006) 5-15.

[6] R. David, M.P. Richter, A.G. Beck-Sickinger, Expressed protein ligation: method and applications, Eur. J. Biochem. 271 (2004) 663-677.

[7] R.C.S. Luz, A.B. Moreira, F.S. Damos, A.A. Tanaka, L.T. Kubota, Cobalt tetrasulphonated phthalocyanine immobilized on poly-L-lysine film onto glassy carbon electrode as amperometric sensor for cysteien, J. Pharm. Biomed. Anal. 42 (2006) 184-191.

[8] S. Shahrokhian, Lead phthalocyanine as a selective carrier for preparation of a cysteine-selective electrode, Anal. Chem. 73 (2001) 59725978.

[9] S. Shahrokhian, M. Karimi, Voltammetric studies of a cobalt(II)-4methylsalophen modified carbon-paste electrode and its application for the simultaneous determination of cysteine and ascorbic acid, Electrochim. Acta 50 (2004) 77-84.

[10] H. Wang, W.S. Wang, H.S. Zhang, Spectrofluorimetic determination of cysteine based on the fluorescence inhibition of Cd(II)-8-hydroxyquinoline5-sulphonic acid complex by cysteine, Talanta 53 (2001) 1015-1019.

[11] D. Zhang, M. Zhang, Z. Liu, M. Yu, F. Li, T. Yi, C. Huang, Highly selective colorimetric sensor for cysteine and homocysteine based on azo derivatives, Tetrahedron Lett. 47 (2006) 7093-7096.

[12] N. Spãtaru, B.V. Sarada, E. Popa, D.A. Tryk, A. Fujishima, Voltammetric determination of L-cysteine at conductive diamond electrodes, Anal. Chem. 73 (2001) 514-519.

[13] W. Hou, E. Wang, Liquid chromatography with electrocatalytic detection of cysteine, $N$-acetylcysteine, and glutathione by a Prussian blue modified electrode, J. Electroanal. Chem. 316 (1991) 155-163.

[14] S. Zhang, W. Sun, W. Zhang, W. Qi, L. Jin, K. Yamamoto, S. Tao, J. Jin, Determination of thiocompounds by liquid chromatography with amperometric detection at a Nafion/indium hexacyanoferrate film modified electrode, Anal. Chim. Acta 386 (1999) 21-30.

[15] P.M.S. Monk, R.J. Mortimer, D.R. Rosseinsky, Electrochromism: Fundamentals and Applications, VCH, Weinheim, Germany, 1995.

[16] K. Itaya, I. Uchida, V.D. Neff, Electrochemistry of polynuclear transition metal cyanides: Prussian blue and its analogues, Acc. Chem. Res. 19 (1986) 162-168.

[17] P.R. Somani, S. Radharkrishnan, Electrochromic materials and devices: present and future, Mater. Chem. Phys. 77 (2003) 117-133.

[18] A.A. Karyakin, E.E. Karyakina, Prussian blue-based "artificial peroxidase" as a transducer for hydrogen peroxide detection: application to biosensors, Sens. Actuators B 57 (1999) 268-273.

[19] Q. Chi, S. Dong, Amperometric biosensors based on the immobilization of oxidases in a Prussian blue film by electrochemical codeposition, Anal. Chim. Acta 310 (1995) 429-436.

[20] D. Moscone, D. D’Ottavi, D. Compagnone, G. Palleschi, A. Amine, Construction and analytical characterization of Prussian blue based carbon paste electrodes and their assembly as oxidase enzyme sensors, Anal. Chem. 73 (2001) 2529-2535.

[21] R. Garjonyte, A. Malinauska, Operational stability of amperometric hydrogen peroxide sensors, based on ferrous and copper hexacyanoferrates, Sens. Actuators B 56 (1999) 93-97.

[22] I.L. de Mattos, L. Gorton, T. Ruzgas, Sensor and biosensor based on Prussian blue modified gold and platinum screen printed electrodes, Biosens. Bioelectron. 18 (2003) 193-200. 
[23] K.-C. Ho, C.-Y. Chen, H.-C. Hsu, L.-C. Chen, S.-C. Shiesh, X.-Z. Lin, Amperometric detection of morphine at a Prussian blue modified indium tin oxide electrode, Biosens. Bioelectron. 20 (2004) 3-8.

[24] K.-S. Tseng, L.-C. Chen, K.-C. Ho, Amperometric detection of $\mathrm{H}_{2} \mathrm{O}_{2}$ at the Prussian blue modified F-doped tin oxide electrode, Sens. Actuators B 108 (2005) 738-745.

[25] K. Itaya, H. Akahoshi, S. Toshima, Electrochemistry of Prussian blue modified electrodes: an electrochemical preparation method, J. Electrochem. Soc. 129 (1982) 1498-1500.

[26] K.-C. Ho, C.-L. Lin, A novel potassium ion sensing based on Prussian blue thin films, Sens. Actuators B 76 (2001) 512-518.

[27] A.A. Karyakin, O. Gitelmacher, E.E. Kayakina, A high-sensitive glucose amperometric biosensor based on Prussian blue modified electrodes, Anal. Lett. 27 (1994) 2861-2869.

[28] A.A. Karyakin, E.E. Karyakina, L. Gorton, Prussian blue based amperometric biosensors in flow-injection analysis, Talanta 43 (1996) 1597-1606.

[29] J. Li, T. Peng, Y. Peng, A cholesterol biosensor based on entrapment of cholesterol oxidase in a silica sol-gel matrix at a Prussian blue modified electrode, Electroanalysis 15 (2003) 1031-1037.

[30] A.A. Karyakin, Prussian blue and its analogues: electrochemistry and analytical applications, Electroanalysis 13 (2001) 813-819.

[31] F. Ricci, G. Palleschi, Sensor and biosensor preparation, optimization and applications of Prussian blue modified electrodes, Biosens. Bioelectron. 21 (2005) 389-407.

[32] R. Koncki, O.S. Wolfbeis, Optical chemical sensing based on thin films of Prussian blue, Sens. Actuators B 51 (1998) 355-358.

[33] R. Koncki, T. Lenarczuk, S. Głąb, Optical sensing schemes for Prussian blue/Prussian white film system, Anal. Chim. Acta 424 (2000) 27-35.

[34] T. Lenarczuk, S. Głąb, R. Koncki, Application of Prussian blue-based optical sensor in pharmaceutical analysis, J. Pharm. Biomed. Anal. 26 (2001) 163-169.

[35] T. Lenarczuk, D. Wencel, S. Głąb, R. Koncki, Prussian blue-based optical glucose biosensor in flow-injection analysis, Anal. Chim. Acta 447 (2001) $23-32$.

[36] A. Radomska, S. Głąb, R. Koncki, Spectrophotometric bioanalytical flowinjection system for control of hemodialysis treatment, Analyst 126 (2001) 1564-1567.
[37] M.J. Ruedas Rama, A. Ruiz Medina, A. Molina Diaz, A Prussian bluebased flow-through renewable surface optosensor for analysis of ascorbic acid, Microchem. J. 78 (2004) 157-162.

[38] L.-C. Chen, K.-C. Ho, Nonlinear diffusion behavior for the Prussian blue electrode: I. Variable diffusivity revealed by potentiostatic intermittent titration technique-chronoabsorptometry, J. Electrochem. Soc. 148 (2001) E282-E289.

[39] G. Chwatko, E. Bald, Detection of cysteine in human plasma by high-performance liquid chromatography and ultraviolet detection after pre-column derivatization with 2-chloro-1-methylpyridinium iodine, Talanta 52 (2000) 509-515.

\section{Biographies}

Lin-Chi Chen received his BS degree in chemical engineering from National Taiwan University, Taipei, Taiwan in 1997. He received PhD degree in chemical engineering from National Taiwan University in 2001. He was a postdoctoral research fellow in the Institute of Biomedical Sciences at Academia Sinica, Taipei, Taiwan, from 2002 until 2005. Currently, he is an assistant professor jointly appointed by the Department of Bio-industrial Mechatronics Engineering and Bioenergy Research Center at National Taiwan University. His research interest includes electrochromic devices, biosensors, biochips and antibody mimics.

Kuo-Chuan Ho received BS and MS degrees in chemical engineering from National Cheng Kung University, Tainan, Taiwan, in 1978 and 1980, respectively. In 1986, he received the $\mathrm{PhD}$ degree in chemical engineering at the University of Rochester. The same year he joined PPG Industries, Inc., first as a senior research engineer and then, from 1990 until 1993, as a research project engineer. He has worked on the electrochemical properties of various electrode materials, with emphasis on improving the performances of sensor devices. Following a 6-year industrial career at PPG Industries, Inc., he joined his alma mater at National Cheng Kung University in 1993 as an associate professor in the Chemical Engineering Department. In 1994, he moved to the Department of Chemical Engineering at National Taiwan University. Currently, he is a professor jointly appointed by the Department of Chemical Engineering and Institute of Polymer Science and Engineering at National Taiwan University. 